\title{
Controle social em saúde: 0 caso do Pará
}

\author{
Social control in health: Parás case
}

Solange Conceição Albuquerque de Cristo*

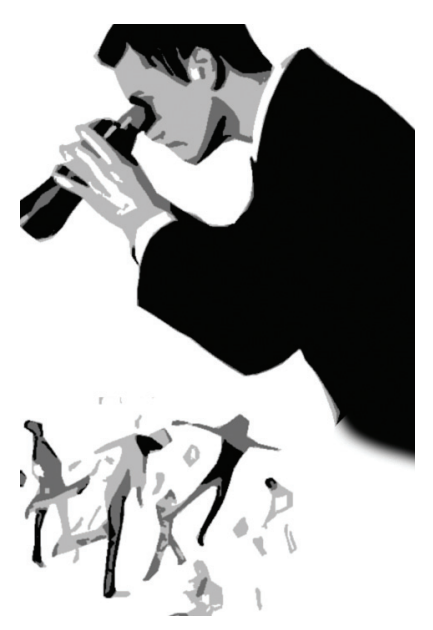

Resumo: Este artigo objetiva contribuir para um exame mais circunstanciado das experiências de controle social. De acordo com o Cadastro dos Conselhos Municipais de Saúde no Brasil (2006), quase um terço da presidência dos Conselhos de Saúde no Pará é ocupada por representantes do segmento dos usuários. As análises desenvolvidas, a partir de entrevistas realizadas com presidentes de dois conselhos no Pará, permitiram compreender os desafios que os Conselhos de Saúde vêm enfrentando para participar da formulação e estratégias de implantação da política de saúde definida na Constituição Federal de 1988, considerando-se as diferenças socioeconômicas regionais, o desenvolvimento das redes locais de serviços de saúde e o acesso da população.

Palavras-chave: Controle social. Conselhos municipais de saúde. Participação. Usuários. Política de saúde.

\begin{abstract}
This article aims at contributing to a detailed examination of the experiences of social control. According to the register of the municipal health councils in Brazil (2006), almost one third of the presidents of the health councils in Pará are representatives of the segment of users. The analysis developed from interviews with the presidents of two councils allows to understand the challenges facing health councils so that they can participate in the formulation and implementation of strategies for health policy function as it is established in 1988's Federal Constitution, considering the socio-economic regional differences, the development of local networks of health services and universal access.
\end{abstract}

Keywords: Social control. Municipal health councils. Participation. Users. Health policy.

\footnotetext{
* Graduada em Serviço Social, especialista em Políticas Sociais, mestre em Serviço Social pela UFPA e doutora em Serviço Social pela PUC-SP — São Paulo/SP, Brasil. É assistente social do Hospital das Clínicas da Faculdade de Medicina da Universidade de São Paulo - HCFMU-SP, Brasil. E-mail: scacristo@yahoo.com.br.
} 


\section{Introdução}

controle social tem sido o centro das discussões e práticas recentes
de diversos segmentos da sociedade como sinônimo de participação
social nas políticas públicas, em especial na de saúde. O conceito
ganhou importância no Brasil a partir do processo de democratização, na década de 1980, e, principalmente, com a institucionalização dos mecanismos de participação nas políticas públicas na Constituição de 1988 . Naquele momento a participação foi concebida na perspectiva de controle social exercido por segmentos da sociedade civil sobre as ações do Estado, no sentido de este atender aos interesses da maioria da população.

O setor de saúde foi pioneiro nesse processo, motivado pelo Movimento da Reforma Sanitária, que reuniu movimentos sociais, intelectuais e partidos políticos de esquerda na luta contra a ditadura militar, e com vistas à mudança do modelo "médico-assistencial privatista" dominante no país (Mendes, 1994) para um Sistema Universal de Saúde Público, participativo, descentralizado e de qualidade. Hoje existem, aproximadamente, 5.559 conselhos municipais de saúde (CMS) atingindo quase a totalidade dos municípios brasileiros (5.560), e implicando cerca de 72 mil conselheiros titulares (dos quais aproximadamente 36 mil representam os usuários da saúde pública). Portanto, novos sujeitos políticos passaram a participar do processo de implantação do Sistema Único de Saúde (SUS), produzindo um cenário sociopolítico incomum na história do país e das democracias contemporâneas (Escorel et al., 2006).

O SUS é uma nova formulação de política e de organização para o reordenamento dos serviços e ações de saúde, estabelecida pela Constituição de 1988 e, posteriormente, pelas leis que a regulamentam. O SUS há que ser entendido, de acordo com a legislação, em seus objetivos finais: dar assistência à população baseada no modelo da promoção, proteção e recuperação da saúde. Estes meios, orientados pelos princípios organizativos da descentralização, regionalização, hierarquização, resolutividade, participação social e complementaridade do setor privado, devem constituir-se em objetivos estratégicos que deem concretude ao modelo de atenção à saúde desejada (Consaúde/SUS, 2006).

Introduziu-se nesse cenário os conselhos de saúde, em conformidade com a Constituição da República Federativa do Brasil, Título VIII, Capítulo II, e as Leis federais ns. 8.080/90 e 8.142/90: Conselhos Municipais de Saúde (CMS), 
como órgãos permanentes, deliberativos e normativos do SUS no âmbito municipal, que têm por competência formular estratégias e controlar a execução da política de saúde do município, inclusive nos seus aspectos econômicos e financeiros.

A Lei n. 8.142/90 preconiza a obrigatoriedade de organização e funcionamento dos CMS, em caráter permanente e deliberativo, compostos por representantes dos trabalhadores de saúde, usuários, gestores e prestadores de serviços. Por serem de composição paritária (50\% de usuários, $25 \%$ de trabalhadores de saúde e $25 \%$ de gestores e prestadores de serviços), os conselhos devem possibilitar à população o exercício da autonomia e da responsabilidade, por meio da formulação de estratégias e controle da execução da política de saúde vigente (Brasil, 1990).

Os Conselhos de Saúde são instâncias políticas de caráter permanente e deliberativo, órgãos colegiados que possuem como uma de suas principais atribuições propiciar a participação da sociedade civil organizada e dos usuários do SUS na discussão institucionalizada do ciclo de políticas de saúde dos estados e municípios. No entanto, a pesquisa de Monitoramento e Apoio à Gestão Participativa do Sistema Único de Saúde (SUS), desenvolvida pelo Ministério da Saúde, revela as dificuldades para o estabelecimento de canais participatórios ou para a participação da sociedade civil, devido à fragilidade das instituições políticas e das instituições da própria sociedade civil (Escorel et al., 2006).

\section{Bases conceituais para a análise do controle social}

Stotz (2006) ressalta que o controle social entendido como participação da sociedade, no âmbito das políticas públicas, ainda não fazia parte da consciência política, principalmente, dos que realizaram a $8^{\text {a }}$ Conferência Nacional de Saúde (Conferência Nacional de Saúde, 1986). Naquele momento mencionava-se apenas "participação da comunidade", que faz parte de um ideário de participação limitada, e tem como objetivo a mera prestação de serviços à comunidade ou à sua organização isolada.

O uso do termo "controle social" apareceu somente em 1992, na $9^{\text {a Con- }}$ ferência Nacional de Saúde, em que a participação social passou a ser definida como "o controle social sobre políticas e atividades desenvolvidas com a Se- 
guridade Social" (Guizard et al., 2004, p. 22, apud Stotz, 2006, p. 152). A mudança de concepção da $8^{\mathrm{a}}$ para a $9^{\mathrm{a}}$ Conferência Nacional decorreu do temor da perda de autonomia dos movimentos sociais - o texto do relatório final da $9^{\text {a }}$ Conferência é explícito no que se refere a esse assunto:

[...] é importante que os movimentos populares criem e mantenham seus foros independentes e autônomos, buscando a discussão dos problemas e as soluções para as questões da saúde, numa perspectiva transformadora. [...] A preservação da autonomia e a independência dos movimentos sociais é fundamental para impedir a sua instrumentalização. (Conferência Nacional de Saúde, 1992, p. 33)

É essencial o aprofundamento da compreensão sobre o controle social a partir de uma concepção de Estado e de sociedade civil, pois ele ocorre nesses eixos. O conceito de sociedade civil em Gramsci (2000-2002) permite compreendê-la como espaço de mediação entre o Estado e as classes sociais. É espaço sociológico objetivo do Estado; não perde vínculo de determinação com a economia. Espaço para organizar a luta pela hegemonia política e ideológica. É o conjunto dos aparelhos privados de hegemonia, permitindo, nessa formulação, um conceito ampliado de Estado.

Na compreensão do conceito acima mencionado, Gramsci (2000-2002) considera duas instâncias no que se refere à relação Estado e sociedade civil: a superestrutura e infraestrutura. A primeira comporta a sociedade civil (espaço do consenso; espaço de hegemonia, ou seja, direção política, aparelhos privados de hegemonia) e a sociedade política (espaço da dominação, espaço da coerção, aparelhos estatais, aparelhos de segurança); a segunda comporta as classes, capital e trabalho. Esses aspectos vão compor o que Gramsci denominou de bloco histórico, como uma unidade de coisas distintas, dotadas de autonomias relativas, ou seja, é unidade e distinção. São constituídas por grandes alianças políticas de classe, de médio a longo prazo, fusão cultural, diversidade na ação política (Gramsci, 2000).

O Estado em Gramsci reúne, além da sociedade política, a sociedade civil com seus aparelhos de hegemonia, que mantêm o consenso, ou seja, "Estado é todo o complexo de atividades práticas e teóricas com os quais a classe dirigente não só justifica e mantém seu domínio, mas consegue obter o consenso ativo dos governados" (Gramsci, 2000, p. 331). Na afirmação de Nogueira (1999, p. 139): 
Gramsci não é um idealista, não supõe uma separação entre o mundo da vida e o mundo da política nem transfere o poder de determinação para o plano político-ideológico, para a sociedade civil. Ao contrário, preocupa-se sempre em ressaltar os elementos de identidade/distinção que fazem com que estrutura e superestrutura (e, no interior dessa, a sociedade civil e a sociedade política) possam ser vistas como partes de um mesmo "bloco histórico". A Gramsci interessa, sobretudo, o momento unitário a captura da "unidade dos contrários e dos distintos" tão cara à dialética, não para cancelar ou diluir a complexidade e as várias especificações do todo (como faria um marxismo positivisticamente determinista), mas para apreender as mediações e articulações que dão sentido às coisas.

Para Nogueira (1999), a sociedade civil gramsciana está fixada no mundo das necessidades materiais, estabelecendo com esse mundo uma relação de pertencimento e negação. É na sociedade civil que os grupos lutam pela hegemonia, quer dizer, pela possibilidade de imprimir ao conjunto dos homens e mulheres uma nova forma de consenso e consentimento. "É na sociedade civil que a sociedade se politiza e se organiza para a disputa do poder" (p. 139).

Criados pela crise e pelo conflito, os espaços públicos caracterizam momentos e práticas que se diferenciam em sua eficácia democratizante de acordo com a maior ou menor proximidade entre os projetos políticos que permeiam as relações entre Estado e sociedade civil.

Assim, a mediação dos projetos políticos ganha importância explicativa porque "a clivagem estrutural entre Estado e sociedade civil não é suficiente para entender as suas relações e deve ser combinada com outras clivagens que não necessariamente coincidem com ela, mas a atravessam" (Dagnino, 2002, p. 281). Esse fato é reafirmado quando se tem em vista a expansão para a esfera do Estado de alguns projetos democratizantes que nasceram na sociedade civil. Dagnino (2002, p. 282) afirma que avaliar:

o impacto da sociedade civil sobre o desempenho do Estado (governance) é uma tarefa que não pode se apoiar num entendimento abstrato dessas categorias como compartimentos separados, mas precisa contemplar aquilo que as articula e as separa, inclusive aquilo que une e opõe as diferentes forças que as integram, os conjuntos de interesses expressos em escolhas políticas: aquilo que está sendo aqui designado como projetos políticos.

A autora usa o termo projeto político "num sentido próximo da visão gramsciana, para designar os conjuntos de crenças, interesses, concepções de 
mundo, representações do que deve ser a vida em sociedade, que orientam a ação política dos diferentes sujeitos" (2002, p. 282).

A análise dessas ações é discutida a partir das formas, das concepções e da natureza da participação da sociedade civil e de seus conflitos com o Estado. As diversas concepções, articuladas a projetos políticos, estão no centro dos conflitos pela formulação e controle social das políticas públicas por parte da sociedade civil e das várias formas de resistência que o Estado oferece a essas ações.

Para Carvalho (1995) “controle social é expressão de uso recente e corresponde a uma moderna compreensão da relação Estado-sociedade, onde a esta cabe estabelecer práticas de vigilância e controle sobre aquele". Para o autor, a concepção de controle social guia os Conselhos de Saúde para que, com a participação de segmentos sociais tradicionalmente excluídos, possam controlar o Estado, "assegurando políticas de saúde pautadas pelas necessidades do conjunto social, e não somente pelos desígnios de seus setores mais privilegiados" (Carvalho, 1995, p. 28).

O conceito de controle social, segundo Paz (2002), indica, em linhas gerais, a capacidade que a sociedade organizada tem de intervir nas políticas públicas, interagindo com o Estado na definição de prioridades e na elaboração dos planos de ação para o município, estado, ou o governo federal. São as ações que visam fiscalizar, acompanhar e avaliar as condições de gestão, a execução das ações e a aplicação dos recursos financeiros destinados à implementação de uma política pública.

\section{Processo da pesquisa junto aos conselhos de saúde}

Pretendeu-se com este artigo desenvolver uma reflexão sobre as possibilidades e desafios para o exercício do controle social, em especial no estado do Pará, na perspectiva da democratização do Estado e da sociedade. E, ao mesmo tempo, contribuir para um exame mais circunstanciado das experiências de controle social, especificamente na área da saúde, destacando-se a participação do segmento dos usuários nos conselhos municipais de saúde.

Os resultados parciais da pesquisa de Monitoramento e Apoio à Gestão Participativa do Sistema Único de Saúde (SUS), desenvolvida desde 2003 pela 
Secretaria de Gestão Estratégica e Participativa do Ministério da Saúde (Segep/ MS), enfocando o grau de democratização dos Conselhos Municipais e Estaduais de Saúde no Brasil, foram importantes para estabelecer um marco de referência para o tema. Essa pesquisa trabalhou inicialmente com um universo de 4.861 conselhos municipais de saúde (CMS) e de 27 conselhos estaduais de saúde (CES), revelando um grau de democratização dos conselhos abaixo do esperado (Escorel et al., 2006).

Ao traçar o perfil dos Conselhos de Saúde no Brasil, Escorel et al. (2006) indicaram que no estado do Pará, em comparação com os demais estados do país, estava havendo uma presença maior do segmento dos usuários na presidência dos Conselhos de Saúde, pois em quase um terço deles essa situação foi constatada.

Foram escolhidos dois municípios do estado do Pará: o município da capital, Belém e o município de Melgaço, levando-se em conta o Índice de Desenvolvimento Humano (PNUD, 2000) (o maior e o menor do estado), o número de equipamentos de saúde (com o maior número e com o menor número), a regional de saúde (a mais e a menos populosa), e o município de mais fácil acesso e o de mais difícil acesso.

Belém é a capital do estado, localizada no extremo Norte do Brasil, e faz parte da região metropolitana do Pará, apresentou o maior Índice de Desenvolvimento Humano (IDH) do estado em 2000, 0,806 (PNUD, 2000). É onde se concentra a maior parte da população, com 1.437.600 habitantes (IBGE, 2010), e tem a maior e mais complexa rede de serviços de saúde: Belém é uma referência na saúde entre os estados nortistas, com a maior média da região, 4,8 postos médicos para cada mil habitantes. Possui, de acordo com dados do IBGE (2010), 1.669 leitos públicos e 2.364 leitos privados; tem 83 estabelecimentos de saúde públicos e 194 privados.

Melgaço, localizado na foz do rio Amazonas, faz parte do arquipélago da Ilha de Marajó. É um município pequeno, com 17.657 habitantes (IBGE, 2010); de difícil acesso, o qual é feito apenas por barco, e com um tempo de viagem aproximado de doze a dezoito horas da capital. Apresentou o menor IDH do estado em 2000 (PNUD, 2000), isto é, 0,525. Até 2009 havia em Melgaço apenas um posto de saúde. O primeiro hospital municipal, classificado como de pequeno porte, inaugurado em meados de junho a início de agosto de 2010, dispõe de quinze leitos nas clínicas de ginecologia e obstetrícia, pediatria e 
clínicas médica e cirúrgica. No entanto, não estava conseguindo fixar médicos no local, em virtude, principalmente, do difícil acesso ao município.

Após a caracterização inicial dos municípios escolhidos, entrevistou-se os presidentes de seus Conselhos Municipais de Saúde, que exerceram mandatos nos períodos de 2010/11, o presidente do Conselho de Belém e 2006/07-2008/09, o presidente do Conselho de Melgaço, com o objetivo de apontar aspectos sobre o perfil dessas pessoas; as dificuldades de organização e mobilização; o exercício do controle social; a dinâmica das reuniões para as avaliações, análises e aprovação de planos, programas e projetos; e os desafios para os próximos anos.

\section{Resultados}

O Conselho Municipal de Saúde de Melgaço, formado em 1996, apresentou na sua composição uma representação numérica maior de representantes do segmento de profissionais de saúde, dada a dificuldade em contar com representantes do segmento dos usuários.

A Secretária de Saúde acabou indicando as entidades que deveriam representar os usuários, esperando que elas participassem das reuniões, mas mesmo assim, nos primeiros anos, teve que reiterar o convite para a participação dessas entidades, antes de cada reunião, por meio de ofícios. A partir do ano 2000 houve alguns avanços, e as entidades passaram a participar mais. O presidente do Conselho Municipal de Saúde, de 29 anos, formado em Pedagogia e respondendo, no período da entrevista, pela direção da escola onde é professor concursado, considera que o Conselho de Saúde do município, embora existindo há catorze anos, ainda está em processo de construção, e precisa "avançar muito, (porque) não se tem ainda uma cultura de participação efetiva nos Conselhos". O Conselho deve exercer uma ação importante de controle social, e quando não há uma fiscalização, sem um acompanhamento das ações de saúde, "fica muito fácil para os governantes fazerem aquilo que bem entendem".

Referindo-se a comentários de que se os conselheiros fossem remunerados poderiam melhorar sua participação, especialmente no caso dos usuários, o entrevistado considerou que com isto se perderia a finalidade dos Conselhos, do próprio controle social: "os conselhos surgiram para estar governando junto, ajudando o município, na busca de uma sociedade melhor”. 
A questão da pequena participação dos conselheiros de saúde em Melgaço, atribuída à situação geográfica, às dificuldades de acesso, à distribuição irregular da população no território, e à situação socioeconômica da maioria das famílias, constituía um importante fator de preocupação para o presidente do Conselho Municipal, pois para ele o "município para se desenvolver precisa de cidadãos comprometidos com a garantia de direitos como saúde, educação, moradia, saneamento básico".

Os demais conselheiros sabiam que de acordo com a Constituição Federal de 1988, a população tinha o direito de ter suas necessidades de saúde atendidas, mas o município não tinha condições de ofertar ou garantir esse atendimento.

No que se refere à prestação de contas, os conselheiros, exigiram a presença de um técnico para auxiliá-los, porque havia algumas "linguagens financeiras" que eles precisavam entender. O Conselho tinha em mãos a receita do município a ser investida em saúde e percebia que os recursos eram insuficientes para manter um médico por quinze dias. Buscavam entender também o porquê de algumas ações não serem realizadas no município, que até pouco tempo só dispunha da atenção básica na saúde, ou seja, "só realizava aquilo que é básico: curativo, atendimento médico.”

Com a intenção de ajudar e menos de entrar em conflito com a gestão da Secretaria de Saúde, eles sempre conseguiram apoio, diferentemente de outros Conselhos de outros municípios, em que, segundo o entrevistado, existiu "muita briga" com a Secretaria, com perdas para a população: [...] "por algum interesse próprio, por algum partidarismo é a população que perde, pois não há fiscalização". Em virtude disto, o presidente do Conselho afirmava que para ele, o Conselho deveria ser visto como um parceiro da Secretaria Municipal de Saúde. E a "comunidade sempre procurava o Conselho para fazer denúncias", em determinada época contra os agentes comunitários de saúde (ACS), porque na área rural eles não visitavam as famílias. Nessas situações, os conselheiros chamavam os trabalhadores de saúde para conversar, puniam alguns pelo descaso, a falta de compromisso com o trabalho; médicos e enfermeiros também foram chamados.

Além disto, o conselho municipal de saúde sempre procurou verificar os registros profissionais dos trabalhadores do Programa Estratégia Saúde da Família (Pesf), pois a maioria era de fora do estado do Pará. Muitos vinham de Minas Gerais, já que o município não dispunha de técnicos especializados. 
Considerava o presidente do Conselho que os profissionais de outros estados iam para o município interessados apenas no emprego, ficavam de seis meses a um ano e depois iam embora. Diante deste fato, o Conselho temia contar com pessoas que não fossem profissionais e exigia da Secretaria Municipal de Saúde a comprovação do registro deles nos Conselhos Regionais de Medicina, Odontologia ou de Enfermagem.

O maior desafio para os próximos anos será motivar os conselheiros para realizar sua função da melhor maneira possível. É preciso saber que ser conselheiro, segundo ele, muitas vezes, "é desagradar muitas pessoas", é falar a verdade quando tem toda uma situação contra, e cobrar.

Enquanto foi presidente do Conselho, posicionou-se terminantemente contra as privatizações, as terceirizações na área da saúde, porque, de alguma forma, quem sai prejudicado é o usuário. O governo devia dobrar o volume de recursos financeiros investidos na saúde. Fazendo uma avaliação do sistema, considera que houve avanços na atenção à saúde no município, mas ainda persistem problemas, especialmente ligados à gestão: "Melhorou, porque veio mais recursos, mas às vezes o problema não é nem tanto o recurso, é de gestão realmente, de gestão". Define-se pessoalmente como um militante e defensor dos SUS por acreditar em suas diretrizes, naquilo que foi proposto, quando foi criado. Na prática, o sistema tem conseguido atender às necessidades básicas da população, embora não de forma plena como deveria ser, permanecendo certo nível de precariedade na atenção. Entende que o SUS precisa ser valorizado pelos brasileiros, principalmente pelos conselheiros de saúde, pois é "onde estamos nós, precisamos do SUS, [...] saúde é algo realmente muito sério que a gente viveu isso enquanto estava no Conselho, né, e hoje não totalmente desligado do Conselho de Saúde porque a gente usa esse sistema”.

Avalia ainda que as lutas são muitas, mas tem percebido alguns avanços. Quando começou a participar do Conselho de Saúde em Melgaço, contavam com uma secretária municipal de Saúde que contribuiu muito para o desenvolvimento da atenção à saúde do município, “deu uma outra cara para a Secretaria, trouxe profissionais, motos, 'ambulanchas', reformou muitos postos na área rural, remédios, durou mais dias”. Hoje o município conta também com um Hospital Regional em Breves (município próximo), e os moradores de Melgaço não precisarão ir para Belém em busca de atendimentos mais complexos, pois poderão ser encontrados na região. 
Ressaltou que o SUS está sendo implantado há apenas vinte anos, e o município também é bastante novo e precisa ser construída muita coisa. As gestões municipais que passaram anteriormente contribuíram bastante, o atual prefeito também tem se empenhado para fazer com que sejam garantidos os projetos da área da saúde. Atualmente contam com quatro enfermeiros, e até três anos atrás isto era "praticamente uma utopia", pois só tinha um profissional que residia no município. Atualmente, às vezes, conseguem cinco ou seis enfermeiros, e dois ou três médicos.

A realidade do Conselho Municipal de Saúde de Belém, capital do estado, segundo o entrevistado, apresenta algumas diferenças: entre os representantes dos usuários, há grande disputa, especialmente entre as entidades que representam a sociedade civil local. Disputam poder e participação, discutem politicamente a distribuição dos recursos, e as demandas são de outro tipo, isto é, mais relacionadas com a organização do sistema de saúde local. No entanto, não se pode afirmar que se tenha um Conselho ideal que exerça o controle social sobre a política de saúde municipal.

Em relação às condições de saúde do município, o presidente do Conselho apontou como necessidade prioritária mais verbas para combater a epidemia de dengue. A cidade apresentava muitos casos de dengue por estar localizada em uma região com altos índices de chuvas durante o ano: "precisamos de mais trabalhadores da dengue na rua", deveriam ser contratados, mas "a lei não permite, pois existe um teto com relação à folha de pagamento do funcionalismo público", fazendo menção à Lei de Responsabilidade Fiscal. Nessas situações, os conselheiros contam com os representantes do Ministério Público para intermediar: "O Ministério Público é parceiro, às vezes vão lá, e assistem às reuniões $[. .$.$] ; o Conselho [. .$.$] é um órgão gestor também, fiscalizador,$ propositivo, $[\ldots]$ "..

Para o entrevistado, o gestor municipal não reconhece a importância que o Conselho tem: pela lei ele deveria enviar a prestação de contas do sistema de saúde local de três em três meses, para o Conselho de Saúde analisar, mas não o faz. Entrega fora do prazo, e os conselheiros acabam tendo pouco tempo para desenvolver suas funções. No Conselho Municipal de Saúde de Belém tudo é documentado para comprovar, porque como um órgão público, qualquer cidadão, qualquer órgão pode pedir a ele algum documento, resolução, e este não pode negar a informação solicitada. 
Relatou que os conselheiros cobram o gestor municipal sobre a demora no atendimento, mas reconhecem que a demanda para os serviços de saúde é muito grande. Não há previsão sobre as necessidades mais frequentes ou especialidades mais procuradas. Com isso, o usuário precisa aguardar, formam-se grandes filas de espera. Embora muitos usuários não entendam a razão dessas dificuldades, os conselheiros sabem que para alguns tipos de atendimento ou especialidade só existe um ou dois especialistas no município, e a demora acaba acontecendo.

Hoje em Belém também existe um grande deficit de médicos nas equipes de Saúde da Família (Pesf), porque esses profissionais não querem trabalhar na Secretaria de Saúde por causa do salário: o SUS estabelece um teto, e os médicos preferem trabalhar nos serviços privados de saúde. A Secretaria de Saúde coloca anúncios para a contratação de médicos, mas poucos se candidatam. Apenas profissionais recém formados se inscrevem. Existe um deficit muito grande de médicos no sistema público de saúde do município, e com isto, "quem sofre são usuários do município". Concorda que o médico ganha pouco, e que o salário pago pelo SUS é baixo, "o mercado oferece um salário muito melhor".

No que diz respeito à discussão e aprovação do Plano Municipal de Saúde (PMS) pelo Conselho Municipal de Saúde, conforme determina a lei, o entrevistado considera que este não tem sido um processo fácil no município. $\mathrm{Na}$ formulação de propostas para o PMS, às vezes há propostas com as quais os conselheiros não concordam, querem acrescentar algo, ou retirar outras, que segundo seu entendimento não se referem à saúde, o que acaba gerando conflito com o gestor municipal. Por outro lado, muitas propostas elaboradas pelos conselheiros não são aceitas pelo gestor. Discutem-se os prós e os contras até chegar a uma conclusão, em que vence a proposta aceitável para todos os segmentos. No geral, o Plano Municipal de Saúde é apresentado pelo gestor, ao Conselho Municipal de Saúde, que pode acrescentar ou retirar propostas.

Existe um prazo regimental para a aprovação do PMS, com tempo para todos os membros do Conselho conhecerem o processo e poder discuti-lo. Os conselheiros podem ter uma cópia do plano e estudá-lo, sendo que contam com uma assessoria técnica e jurídica como suporte, "a gente precisa do socorro desses técnicos aí pra gente, mas, além desses técnicos, a Secretaria Municipal de Saúde também manda os seus técnicos para tirar nossas dúvidas”.

O presidente do Conselho Municipal de Saúde considera que muitos serão os desafios nos próximos anos, e o maior deles será implantar uma estrutura 
suficiente para desenvolver as atividades do Conselho: "Hoje a infraestrutura do Conselho é mínima”. Precisam de um espaço maior para as reuniões e também de auxílio para transporte dos conselheiros, para que estes possam desempenhar suas funções a contento: "[...] às vezes o conselheiro fica até tarde na rua trabalhando porque não tem infraestrutura de lanche, almoço; o conselheiro tem que até meter a mão no bolso pra gastar dentro da sua atividade". Outro desafio que precisa ser enfrentado é a falta de capacitação dos conselheiros para desempenhar suas funções, pois há conselheiros novos sem capacitação.

Apontou ainda que quando algumas pessoas falam que o Conselho "é do prefeito", ele nega, e esclarece que todos os conselheiros sabem das suas funções, os Ministérios Públicos Estadual e Federal, estão lá observando. Mas considera que o Conselho "é um parceiro" da Secretaria de Saúde e do prefeito, "porque nós criamos uma consciência aqui dentro, coletiva, de conselheiro, tudo o que nós pudermos fazer para beneficiar o usuário de saúde, nós vamos fazer, nós não vamos 'engessar'”.

Ressalta que os conselheiros conhecem seus compromissos, e quando cometem irresponsabilidades, podem ser advertidos e responsabilizados, civil ou juridicamente, pelo Ministério Público. Procuram ter muito cuidado, procuram agir com responsabilidade no controle social.

Os conselheiros municipais de saúde estão discutindo com os membros do Conselho Estadual de Saúde sobre a necessidade de uma interação melhor entre a administração estadual e a municipal, para não prejudicar o atendimento aos usuários. Na opinião do entrevistado, "dão mais importância às vezes à burocracia do que ao próprio paciente; eu só vou atender se tiver isso, aquilo, atende o paciente depois a gente resolve o resto...".

Por outro lado, esclarece que existem pessoas que querem que o Conselho execute ações para as quais ele não tem poder. Suas atribuições são fiscalizar, cobrar execução, e quando o município não atende às reivindicações do Conselho, ele pode acionar a Justiça e os Ministérios Públicos Estadual e Federal, embora no caso de Belém o Conselho Municipal nunca tenha recorrido a esse expediente porque considera que o município tem se esforçado para "acertar".

Observou também, com relação aos segmentos que assumem a presidência dos Conselhos de Saúde, que o secretário de Saúde é membro nato, mas, segundo o entrevistado, isto não significa que ele tem que ser o presidente do Conselho: “[...] como é que ele vai fiscalizar ele mesmo, como é que ele vai 
fazer um trabalho... secretário de Saúde e presidente do Conselho? E aí não tinha ética, não tinha $[\ldots . .$. ".

No nível estadual, o secretário estadual de Saúde do Pará é o presidente do Conselho Estadual de Saúde, mas os municípios vêm mudando essa prática há algum tempo: há mais de dez anos, muitos conselhos municipais têm como presidente um representante do segmento dos usuários.

\section{Breve análise dos conselhos de Belém e Melgaço}

Considerando o perfil dos presidentes dos dois Conselhos de Saúde de Melgaço e Belém, podemos observar que o de Melgaço é filiado ao Partido Progressista (PP), e informou que foi a partir do momento em que começou a trabalhar na saúde que passou a se envolver efetivamente com outras entidades, movimentos, conselhos, o que contribuiu para ampliar seu conhecimento sobre a realidade local, sobre as pessoas e o município onde mora. Já o de Belém não é filiado a nenhum partido atualmente, defende e procura divulgar a entidade da qual participa.

Cabe ainda destacar, nos depoimentos obtidos entre os presidentes dos dois conselhos municipais os seguintes aspectos: a dimensão do conhecimento do presidente do Conselho de Belém sobre a realidade de saúde do município ainda é fragmentada, localizada. Já o de Melgaço é mais abrangente, relaciona a saúde com outros aspectos de vida da população, além de estabelecer comparações com outras realidades. Tem clareza das dificuldades e deficiências do Conselho Municipal de Saúde em sua atuação no controle social, e aponta os desafios mais concretos para os próximos anos, principalmente no que se refere à participação da sociedade civil organizada neste espaço.

Com isso, os conselheiros de Saúde, porém, não se transformaram totalmente em meros "carimbadores de despesas" no âmbito dos sistemas municipais e estaduais de saúde. Buscam entender o porquê daquelas ações, e não de outras. Mostram que também têm poder, por meio de uma assinatura que seja, que depende deles a garantia de recursos, mas ao mesmo tempo se mostram inseguros por tamanha responsabilidade.

Percebe-se, na conduta dos dois entrevistados, uma preocupação com a prestação de contas, as contas "estarem corretas". A responsabilidade, e de 
certa maneira o poder que eles têm para garantir que a verba para saúde seja investida no que é prioritário, isso eles procuram entender, e também propor ações que beneficiem a população.

Nota-se o compromisso dos dois entrevistados em analisar os Planos $\mathrm{Mu}-$ nicipais de Saúde, buscando os técnicos quando não entendem algo. Percebe-se ainda que o Conselho realiza ações que não lhe competem: burocracia ou os trâmites documentais constituem obstáculos para os conselheiros conseguirem garantir as ações e serviços necessários para seus municípios, característica mais acentuada na realidade de Belém.

A ajuda de custo para os conselheiros é uma reivindicação de alguns usuários para se fazerem presentes nas discussões da política de saúde, bem mais acentuada na realidade do município de Melgaço. Outra é a necessidade de se contar com uma infraestrutura mínima que dê condição para os conselheiros realizarem suas atividades da melhor maneira possível, mais forte na realidade de Belém.

Conhecendo a realidade do município de Melgaço, onde é difícil manter a presença de médicos, acredita-se que isso ocorra não só lá, mas em outros municípios com realidades parecidas, compreendendo-se assim por que Belém é muito procurada em termos de atendimentos mais complexos e especialidades. Mas como Belém, por sua vez, também apresenta carência de profissionais, a demanda aumenta sempre, ampliando as filas por consultas especializadas.

Na concepção dos presidentes desses dois conselhos, os Conselhos Municipais de Saúde estão menos voltados para estabelecer a estabilidade das relações e sustentar uma determinada correlação de forças, mas devem agir na perspectiva das parcerias com as Secretarias Municipais de Saúde. O embate, ou o conflito, é evitado com o propósito de não prejudicar os usuários do SUS, como se observou nos depoimentos dos presidentes entrevistados dos dois Conselhos aqui abordados.

\section{Considerações finais}

O poder e a autoridade nos Conselhos Municipais de Saúde no Pará, na perspectiva de seus presidentes, como representantes dos usuários, ainda estão longe de ser uma realidade. Percebe-se que as Secretarias Municipais de Saúde 
exercem forte influência nas decisões dos Conselhos, apesar de muitos, no Pará, terem na presidência um representante dos usuários. As administrações municipais muitas vezes consideram os Conselhos um obstáculo para o encaminhamento das suas ações ou aprovação das prestações de contas. Os Planos Municipais de Saúde são apresentados aos conselheiros em sua versão quase final, quando o ideal seria que os Conselhos participassem de sua elaboração. Estes acabam atuando, por vezes, em processos meramente protocolares, com funções legitimadoras das decisões tomadas no interior da estrutura estatal.

Mesmo os conselheiros de Saúde que representam o segmento dos usuários, e conhecem a realidade local, mantém, em alguma medida, uma concepção assistencialista, imediatista e emergencial da política de saúde diante da insuficiência do sistema de saúde para atender as necessidades da população. Mas apresentam simultaneamente uma concepção de coletivo, de organização, de pensar a população como um todo e se colocar nela, como usuário do sistema.

Por outro lado, na visão do gestor, a tendência é pensar apenas do ponto de vista quantitativo na avaliação dos resultados do sistema de saúde, e menos das demandas por qualidade, principalmente nos programas que são desenvolvidos. O desafio é aliar essas duas visões na busca de uma atenção em saúde melhor, mais propositiva.

De acordo com a pesquisa e as análises desenvolvidas, entende-se que os Conselhos Municipais de Saúde no Pará, especialmente em Belém e em Melgaço, não conseguiram ainda cumprir a função de participar na formulação de estratégias da política de saúde. Compreende-se que a participação e o controle social do segmento dos usuários nos CMS é um exercício cotidiano. Recorrem-se aos recursos políticos, técnicos, financeiros, intelectuais próprios ou disponíveis. A participação política, especialmente para entender o esforço do segmento dos usuários em garantir seu espaço nos CMS, satisfaz-se tendo em vista a comunidade como um todo. Ela é uma prática ético-política e tem a ver tanto com a questão do poder e da dominação quanto com a do consenso e da hegemonia, tanto com a coerção quanto com o consentimento. Por interferência da participação política, indivíduos e grupos tentam fazer com que o poder se democratize e seja compartilhado.

Portanto, quando a partilha efetiva do poder está comprometida, restam aos representantes oriundos da sociedade civil funções consultivas, executoras e/ou legitimadoras das decisões tomadas no interior da estrutura estatal. Isto é, a partilha do poder pode, de fato, estar limitada e restrita, sem que haja possi- 
bilidade de esses atores deliberarem sobre as políticas públicas de âmbito mais geral. Como resultado, nota-se também uma institucionalização dos espaços de encontro, que acabam por se configurar como "institucionalidades paralelas" à estrutura estatal.

Dessa forma, a participação da sociedade civil enfrenta limitações que se originam nas estruturas estatais pouco comprometidas com os processos de democratização, na burocratização, na falta de recursos, na ineficácia, na instabilidade dos projetos que implicam a parceria com o Estado e, ainda, na exigência de qualificação técnica e política que deveria dar suporte para manutenção da autonomia e da capacidade de representação efetiva. Como no interior da própria sociedade civil há confronto entre diferentes projetos políticos, concepções e interesses, estes se refletem no interior desses organismos de representação de interesses sociais diferentes. As dificuldades de reconhecimento da pluralidade e da busca de interesses comuns são, de acordo com Dagnino (2002), o núcleo de "um aprendizado" difícil: o da construção da hegemonia.

\section{Recebido em 22/11/2011 - Aprovado em 6/12/2011}

\section{Referências bibliográficas}

BRASIL. Lei Orgânica da Saúde n. 8.142, de 28 de dezembro de 1990. Dispõe sobre a participação da comunidade na gestão do SUS e sobre as transferências intergovernamentais de recursos financeiros na área da saúde e dá outras providências. Diário Oficial [da] República Federativa do Brasil, Brasília, 1990.

CADASTRO Nacional dos Conselhos Municipais de Saúde. Disponível em: <www.conselho.saude.gov.br>. Acesso em: 26 nov. 2009.

CARVALHO, Antonio Ivo de. Conselhos de Saúde no Brasil: participação cidadã e controle social. Rio de Janeiro: Fase, 1995.

CONFERÊNCIA NACIONAL DE SAÚDE, 9., 1992, Brasília. Relatório Final. Brasília: Centro de Documentação do Ministério da Saúde, 1992. Disponível em: <http://conselho. saude.gov.br/biblioteca/relatórios.htm>. Acesso em: 10 jul. 2008.

CONFERÊNCIA NACIONAL DE SAÚDE, 8., 1986, Brasília. Relatório Final. Brasília: Centro de Documentação do Ministério da Saúde, 1986. Disponível em: <http://conselho. saude.gov.br/biblioteca/relatórios.htm>. Acesso em: 10 jul. 2008. 
CONSAÚDE. Sistema Único de Saúde. Informações sobre o Sistema de Saúde Público. Disponível em <http://www.consaude.com.br/sus/indice.htm>. Acesso em: 2 set. 2006.

CRISTO, Solange C. A. Controle social em saúde: uma análise dos Conselhos Municipais de Saúde de Belém e Melgaço no estado do Pará. 2011. Tese (Doutorado) — Programa de Estudos Pós-Graduados em Serviço Social, Pontifícia Universidade Católica, São Paulo, 2011.

DAGNINO, Evelina. Sociedade civil e espaços públicos no Brasil. Rio de Janeiro: Paz e Terra, 2002.

ESCOREL, Sarah et al. A democratização nos Conselhos de Saúde. Saúde em Debate do Centro Brasileiro de Estudos de Saúde, Rio de Janeiro, v. 30, n. 73-74, p. 205-218, maio/ dez. 2006.

GRAMSCI, Antonio. Cadernos do cárcere: temas de cultura. Ação católica. Americanismo e fordismo. Ed. e trad. Carlos Nelson Coutinho; coedição Luiz Sérgio Henriques e Marco Aurélio Nogueira. 2. ed. Rio de Janeiro: Civilização Brasileira, 2007. v. 4.

. Cadernos do cárcere: introdução ao estudo da Filosofia de Benedetto Croce. Ed. e trad. Carlos Nelson Coutinho; coedição Luiz Sérgio Henriques e Marco Aurélio Nogueira. 4. ed. Rio de Janeiro: Civilização Brasileira, 2006. v. 1.

. Cadernos do cárcere: os intelectuais. O princípio educativo. Jornalismo. Ed. e trad. Carlos Nelson Coutinho; coedição Luiz Sérgio Henriques e Marco Aurélio Nogueira. 4. ed. Rio de Janeiro: Civilização Brasileira, 2006. v. 2.

. Cadernos do cárcere: o risorgimento. Notas sobre a história da Itália. Edição e tradução de Luiz Sérgio Henriques; coedição Carlos Nelson Coutinho e Marco Aurélio Nogueira. Rio de Janeiro: Civilização Brasileira, 2002. v. 5.

. Cadernos do cárcere: Maquiavel - notas sobre o Estado e a política. Ed. e trad. Carlos Nelson Coutinho; coedição Luiz Sérgio Henriques e Marco Aurélio Nogueira. 3. ed. Rio de Janeiro: Civilização Brasileira, 2000. v. 3.

INSTITUTO BRASILEIRO DE GEOGRAFIA E ESTATÍSTICA (IBGE). Ministério do Planejamento, Orçamento e Gestão. Coordenação de população e indicadores sociais. Estatísticas da saúde: Assistência Médico-Sanitária (2009). Rio de Janeiro: IBGE, 2010.

MARSIGLIA, Regina. Orientações básicas para a pesquisa. In: MOTA, Ana Elizabete (Org.). Serviço Social e saúde: formação e trabalho profissional. São Paulo: Cortez, OPAS, OMS, Ministério da Saúde, 2006. p. 383-398.

MARTINELLI, Maria Lúcia (Org.). Pesquisa qualitativa: um instigante desafio. São Paulo: Veras, 1999. (Núcleo de Estudos e Pesquisas sobre Identidade — Nepi. Série Núcleo de Pesquisa: 1). 
MENDES, Eugênio Vilaça. Distrito sanitário: o processo social de mudança das práticas sanitárias do Sistema Único de Saúde. 2. ed. São Paulo: Hucitec; Rio de Janeiro: Abrasco, 1994.

NOGUEIRA, Marco Aurélio. Um Gramsci todo dedicado à política. In: FERREIRA, Oliveiros S. Um pensador da política. São Paulo: Humanitas Publicações, 1999. p. 133-156.

PAZ, Rosângela D. O. Dimensões e indicadores de participação social na avaliação de programas habitacionais. 2002. Tese (Doutorado) Programa de Pós-Graduação em Serviço Social, Pontifícia Universidade Católica, São Paulo, 2002.

PROGRAMA DAS NAÇÕES UNIDAS PARA O DESENVOLVIMENTO (PNUD). Relatório de Desenvolvimento Humano, 2000. Disponível em: <http://www.pnud.org.br/rdh/>. Acesso: 20 nov. 2009.

STOTZ, Eduardo. Trajetória, limites e desafios do controle social do SUS. Revista do Centro Brasileiro de Estudos da Saúde, Rio de Janeiro, v. 30, n. 73/74, maio/dez. 2006. 